\title{
EDUCAÇÃO FINANCEIRA: UMA ANÁLISE DE GRUPOS ACADÊMICOS
}

\author{
FINANCIAL EDUCATION: AN ANALYSIS OF ACADEMIC GROUPS
}

\author{
Jefferson Pereira Andrade \\ Universidade Federal da Paraíba - UFPB \\ pereira_jp2008@hotmail.com
}

Wenner Glaucio Lopes Lucena Universidade Federal da Paraíba - UFPB

wdlucena@yahoo.com.br

Submissão: 24/07/2016

Aprovação: 02/06/2018

\begin{abstract}
RESUMO
O presente trabalho teve por objetivo verificar a relação entre o nível de educação financeira de diferentes grupos acadêmicos com as características individuais e o comportamento financeiro desses alunos. A amostra da pesquisa foi composta de 188 alunos do curso de Ciências Contábeis (Para efeito deste artigo foram denominados grupo acadêmico 1) e alunos dos cursos de licenciatura, pedagogia e serviço social (Grupo acadêmico 2). A amostra foi definida a partir dos componentes curriculares dos cursos. Verificou-se que 68 alunos eram do gênero masculino e 120 do gênero feminino, $86 \%$ dos pesquisados afirmaram ser solteiros, $53,7 \%$ possui idade entre 20 e 26 anos e 53,19\% são do curso de Ciências Contábeis. Verificou-se ainda que existe uma relação estatística significativa com relação à graduação e os conhecimentos financeiros, também foi possível perceber essa relação quanto ao gênero dos pesquisado. Verificou-se ainda que os alunos atribuem importância a temas como planejamento financeiro, orçamento, poupança e investimento, entretanto não foi encontrada relações estatísticas com o nível de educação financeira dos alunos. Também foi possível verificar que os alunos mais educados financeiramente demonstram ter mais confiança para gerir as próprias finanças.
\end{abstract}

Palavras-chave: Educação financeira. Finanças pessoais. Decisões financeiras. 


\begin{abstract}
The present study aimed to verify the relationship between the level of financial education of different academic groups with the individual characteristics and the financial behavior of these students. The sample of the research was composed of 188 students of the course of Accounting Sciences (For the purpose of this article were denominated academic group 1) and students of the courses of licentiate, pedagogy and social service (Academic Group 2). The sample was defined from the curricular components of the courses. It was verified that 68 students were males and 120 females, $86 \%$ of those surveyed said they were single, $53.7 \%$ were between 20 and 26 years of age and $53.19 \%$ were students of the Accounting Sciences course. It was also verified that there is a significant statistical relation with the undergraduate and the financial knowledge, it was also possible to perceive this relation as to the gender of the researched ones. It was also verified that the students attribute importance to subjects such as financial planning, budget, savings and investment, however no statistical relationships with the level of financial education of the students were found. It was also possible to verify that the students more educated financially demonstrate to have more confidence to manage their own finances.
\end{abstract}

Keywords: Financial education. Personal finances. Financial decisions. 


\section{INTRODUÇÃO}

De acordo com os dados do SPC (2017), em janeiro de 2017 cerca de 58,3 milhões pessoas possuíam o nome inscrito em programas de proteção ao crédito, representando um aumento de aproximadamente 700 mil nomes em relação ao mesmo período de 2016, mesmo assim, segundo o órgão, deste o terceiro trimestre de 2016 as estimativas de inadimplência têm sofrido uma leve redução ocasionada pela restrição de crédito.

Embora esses sejam dados agregados, ele diz respeito a consequências de decisões privadas. De acordo com Vieira, Bataglia e Sereia (2011) às questões como inadimplência, endividamento familiar e capacidade de planejamento de longo prazo estão intimamente ligadas a qualidades das decisões individuais, e possuem relevância no aspecto macroeconômico (BIROCHI; POZZEBON, 2016).

Geralmente as pessoas não entendem como as decisões são tomadas e quais as consequências disso nos seus resultados alcançados (BAZERMAN; MOORE, 2014). A falta de conhecimento financeiro leva as pessoas a decisões menos eficazes e racionais, além disso, essas pessoas se tornam alheias a diversos conceitos e produtos financeiros ofertados pelo mercado, implicando na educação financeira como uma das ferramentas crucial no que tange às decisões financeiras de um indivíduo (JONSSON; SÖDERBERG; WILHELMSSON, 2017).

Por meio da educação financeira os indivíduos melhoram sua compreensão sobre os produtos financeiros, e os seus riscos, podendo desenvolver habilidades e a confiança necessária para a tomada de decisão segura, e melhorando o seu bem está (POTRICH; VIEIRA; SILVA, 2016). Os resultados das decisões financeiras têm implicações significativas para a segurança financeira e padrão de vidas dos indivíduos (BONGOMIN et al., 2017).

No Brasil, uma criança é capaz de chegar na fase adulta sem o domínio de situações financeiras básicas que vão desde a leitura de um extrato bancário, até administrar seu próprio dinheiro (FREITAG et al., 2009).

Em retrato nacional desenvolvido para a elaboração da Estratégia Nacional de Educação Financeira - ENEF (2008) verificou-se a existência de um descompasso entre a visão profissional e a visão popular no que tange conceitos financeiros, além disso, boa parte da população não consegue fazer o dinheiro render até o fim do mês, demonstrando descontrole das finanças pessoais, também foi constatado a ausência de preocupação no que tange a formação de poupança.

Embora esse seja um diagnóstico a nível de Brasil, Lusardi e Mitchell (2011) destacam que o analfabetismo financeiro corresponde a uma realidade global, evidenciando a necessidade de desenvolvimento de programas de educação que visam oferecer à população conhecimento para uma vida financeira mais saudável, com esse objetivo foi criado o Decreto 7.397 de 2010 cujo objetivo é promover a educação financeira e previdenciária, aumentar a capacidade dos cidadãos para efetuar decisões relacionadas a seus recursos.

A partir desse decreto foi desenvolvida uma mobilização multissetorial em torno da educação financeira no país, denominada Estratégia Nacional de Educação Financeira e que atualmente conta com mais de 1.300 iniciativas voltadas à promoção da educação financeira no país (ENEF, 2018).

Embora seja relevante o acesso de toda a população a esses programas, Haslem (2013) frisa que os programas devem buscar ter foco em grupos mais específicos, ponderando os fatores sociais e econômicos que envolvem cada um. Dessa forma um programa cujo objetivo de promover a educação deve focar em grupos prioritários, sendo relevante a identificação desses grupos. 
Em meio a importância da educação financeira e a necessidade de identificação de grupos prioritários o presente estudo tem por objetivo verificar a relação entre a educação financeira, características individuais, além do comportamento financeiro de estudantes de uma universidade pública da Paraíba.

A pesquisa se justifica por poder contribuir para os debates envolvendo a educação financeira no Brasil, além de possibilitar a identificação dos grupos de risco, principalmente em um momento em que se desenvolve a Estratégia Nacional de Educação Financeira.

$\mathrm{O}$ artigo está estruturado em cinco tópico incluindo a introdução. Nas próximas seções é apresentada a revisão da literatura envolvendo a educação financeira, a metodologia de pesquisa empregada para alcance do objetivo de pesquisa, a análise dos resultados e por fim as considerações finais.

\section{EDUCAÇÃO FINANCEIRA}

Em uma pesquisa recente, Silva et al. (2017) demonstrou o desacordo existente na literatura, no que tange os conceitos relacionados a educação financeira. Para os autores, dois termos são frequentemente utilizados de forma intercambiáveis, sendo eles "educação financeira" e "alfabetização financeira".

A alfabetização financeira é compreenda com um termo mais amplo do que a educação financeira, e de acordo com a OCDE (2011) envolve três dimensões básicas: o conhecimento, a atitude e o comportamento financeiro. Já o vocábulo educação financeira engloba apenas uma das dimensões, o conhecimento financeiro (SILVA et al., 2017).

A partir da compreensão das dimensões de cada um dos termos, é possível perceber que o "conhecimento financeiro" corresponde a um ponto de interseção entre os conceitos, permitindo que ao se tratar do assunto, ambos os termos possam ser utilizados.

A educação financeira representa coisas diferentes para pessoas diferentes, o que é refletido nas definições utilizadas na literatura acadêmica e consequentemente nos conhecimentos que a envolvem (WORTHINGTON, 2006). Para Augustinis, Costa e Barros (2012) ao se tratar de educação financeira, é possível defini-la de forma absoluta, isto é, compreendendo um padrão de conhecimento que seja considerada importante para todos os consumidores, ou relativa, onde os padrões variam de acordo com as habilidades, necessidades e experiências de cada indivíduo.

O conhecimento esperado de um profissional da área de finanças em comparação ao conhecimento da uma pessoa não profissional corresponde a um exemplo onde se origina um conceito relativo de educação financeira, neste contexto a educação do indivíduo profissional deve englobar conhecimentos não exigidos de uma pessoa não profissional definindo assim os conceitos (WORTHINGTON, 2006).

Ao se originar de contexto característicos, os conceitos relativos são pouco usados em comparação com os conceitos absolutos, Savoia, Saito e Santana (2007) por exemplo, descrevem a educação financeira como um processo pelo qual ocorre a transmissão de conhecimentos que permitem os indivíduos desenvolverem habilidades que viabilizem a tomada de decisão fundamentada e segura, melhorando a suas finanças pessoais. Já de acordo com Augustinis, Costa e Barros, (2012, p.84) o conceito de educação financeira "está relacionado ao método pelo qual se pode alcançar as competências necessárias para a compreensão de questões relativas à economia e a finanças".

Quanto a competências, Hira (2009) aponta que ser educado financeiramente significa estar bem informado sobre assuntos como dinheiro, crédito, investimentos, bancos, seguros, impostos e gestão financeira (por exemplo, risco, perda, ganho), além de ser dotado da capacidade de usar esse conhecimento para planejar e tomar decisões financeiras corretas. Já de acordo com a Organização para a Cooperação e Desenvolvimento Econômico - OCDE 
(2005) uma pessoa educada financeiramente deve deter a capacidade de gerir suas finanças pessoais através de processos que envolvem orçamentos, poupança e investimento.

A partir dessas habilidades e que os indivíduos tomam decisões baseadas em conhecimentos sólidos, podendo contribuir para a maior eficiência e estabilidade de recursos financeiros em nível micro e macro da economia (KLAPPER; LUSARDI; PANOS, 2012). Pessoas mais educadas financeiramente são mais propensas a ter maior disponibilidade de renda e menor endividamento (KLAPPER; LUSARDI; PANOS, 2012); possuem a maior direcionamento a poupança e preparação à aposentadoria (LUSARDI; MITCHELL, 2006, 2011).

As decisões financeiras tomadas pelos consumidores afetam o bem-estar financeiro atual de um (a) indivíduo/ família e a capacidade de economizar para metas de longo prazo, como comprar uma casa, buscar educação superior ou financiar a aposentadoria. Além disso, as decisões dos consumidores também desempenham um papel importante na saúde econômica geral do país, como foi vivenciado na crise econômica de 2008 (HIRA, 2009).

Mais do que nunca, o mercado financeiro tem se tornado cada vez mais acessível aos pequenos investidores, a medida que os novos produtos financeiros se expandem, serviços alternativos como empréstimos, penhores e financiamentos estão se tornando mais difundidos e as mudanças no cenário previdenciário aumenta cada vez mais a necessidade de poupança e investimento para trabalhadores (LUSARDI; MITCHELL, 2013).

A maior complexidade e disponibilidade de produtos financeiros têm demandado das pessoas maior conhecimento sobre o assunto, o que transformou a educação financeira em uma fonte de integração social, contribuindo para que as pessoas possam participar de forma mais ativa na economia e criando um mercado mais competitivo (VIEIRA et al., 2011).

Embora apresente inúmeros benéficos as finanças pessoais e para a economia, a realidade demonstra que as pessoas possuem baixo grau de conhecimento financeiro. Uma pesquisa realizada com a população brasileira pelo Instituto Data Popular, para elaboração da Estratégia Nacional de Educação Financeira (ENEF) em 2008, demonstrou que para os brasileiros o dinheiro é sinônimo de meio de pagamento necessário para o cotidiano e investimento é simplesmente a aquisição de bens como carros e casas. O fato é que as famílias possuem uma visão equivocada do mundo financeiro, há um descompasso entre a visão profissional e a visão da população.

Após pesquisar a educação financeira em oito países Lusardi e Mitchell (2011) concluíram e o analfabetismo financeiro e generalizado, e independente do nível de desenvolvimento econômico do país em questão. As mudanças econômicas não trouxeram benefícios ao conhecimento financeiros dos indivíduos, sugerindo que existe um limite que as pessoas podem aprender sozinho. Nestas circunstancias Lucena e Maciel (2010) alertam para a necessidade de programas de educação financeira com a finalidade de conscientizar e instruir a população sobre conceitos básicos de finanças, principalmente no que tange o crédito, poupança e investimento.

Embora a educação financeira não seja homogênea entre as pessoas, (Indivíduos diferentes possuem conhecimentos diferentes) a literatura tem evidenciado padrões de conhecimento que convergem e divergem entre pesquisas. De acordo com Silva et al. (2017) a partir desses padrões surgiu a oportunidade de se desenvolver políticas governamentais e programas educacionais especificamente voltados para esses grupos. Segundo Haslem (2013) para se alcançar a eficiência de um programa de educação financeira, é necessário ter foco em grupos mais específicos, ponderando os fatores sociais e econômicos que envolvem cada um.

Em um estudo desenvolvido com alunos universitários nos Estados Unidos, Chen e Volpe (2002) identificaram diferenças no nível de conhecimento de homens e mulheres, mesmo quando considerado fatores como idade, especializações e experiência profissional, as mulheres apresentaram conhecimento inferior ao conhecimento dos homens. Os autores 
também conseguiram identificar que as mulheres geralmente possuem pouco entusiasmo, menos confiança e vontade de aprender finanças.

Na Holanda Alessie, Rooij e Lusardi (2011) não encontraram diferença no nível de educação financeira de pessoas em diferentes fases do ciclo de vida. No que tange o gênero, os autores evidenciaram diferenças estatísticas significativas, assim como Chen e Volpe (2002) os resultados indicaram que as mulheres apresentam uma carga menor de conhecimento em relação aos homens, entretanto o os autores salientam que há existência desta diferença não implica dizer que elas erram mais que os homens, mas sim, que elas são mais propensas a afirmarem que não sabem. Quanto ao nível de educação, pessoas com baixo grau de escolaridade estão entre os que detém menor conhecimento, poucas pessoas que cursaram até ensino fundamental conseguem responder corretamente questões envolvendo cálculos simples, inflação e investimentos. Também foram encontradas diferenças entre pessoas ativas o mercado de trabalho e aposentados, sendo que os primeiros apresentaram maior conhecimentos, assim como profissionais liberais.

No estudo desenvolvido por Lusardi e Mitchell (2011) em oito países os autores concluíram que: Nos Estados Unidos as pessoas brancas e de origem asiáticas tendem a serem mais educados financeiramente do que pessoas negras e hispânicas. Na Itália pessoas da região norte e central, demonstraram ser mais preparados financeiramente do que as pessoas da região sul. Na Rússia pessoas que moram em áreas urbanas demonstraram ter um maior grau de conhecimento financeiro em relação a pessoas de zonas rurais. Pessoas originárias dos Países Baixos, praticantes de religiões menos representativas e muçulmanos também demonstram ser menos propensos a apresentarem maior nível de educação financeira.

Na Rússia, Klapper, Lusardi e Panos (2012) a partir de testes univariados efetuados a partir de dados coletados via survey, chegaram à conclusão de que homens casados ou que coabitam, jovens e que residem em áreas urbanas tendem a ser mais educados financeiramente. Também pertencem ao grupo mais sofisticado, pessoas de nível superior, trabalhadores vinculados a profissões não mecânicas e com renda superior.

Já na Franças um estudo desenvolvido por Arrondel, Debbich e Savignic (2013) evidenciou que trabalhadores de meia idade com alto nível de escolaridade tendem a exibir altos níveis de educação financeira. Os resultados ainda sugerem diferenças no conhecimento dos pesquisados no que tange o gênero, e apontam uma relação positiva do conhecimento financeiro e a escolaridade. Foram encontradas diferenças entre trabalhadores empregados e não empregados, mas que não persistiram quando considerada a experiência dos profissionais.

No Brasil Flores, Campara e Vieira (2012) estudaram a educação financeira e a propensão ao endividamento de residentes no município de Santa Maria e constaram existir diferenças estatística entre características como estado civil, renda e escolaridade. Os autores explicam que, com o matrimônio as pessoas passam a apresentarem maior preocupação com as finanças pessoais de forma a buscarem maior estabilidade e aversão ao risco. No que tange a renda a explicação para a diferenças no conhecimento financeiro dos indivíduos pode residir no na tendência de maior renda investirem mais em educação.

A literatura acerca da educação financeira também demonstra que as pessoas são passíveis a variação do seu nível de conhecimento ao longo da vida, variação essa representada pelo padrão em forma de corcunda ou modelo do ciclo de vida (ARRONDEL; DEBBICH; SAVIGNAC, 2013). Nesse modelo as pessoas quando jovens possuem um baixo nível de conhecimento financeiro, pois é nesse período que elas começam a acumular conhecimento, na vida adulta atingem o ápice de seus conhecimentos e quando velhos têm sua capacidade cognitiva reduzida e consequentemente sua habilidade de tomar boas decisões financeiras seguras e fundamentadas também é reduzida (ARRONDEL; DEBBICH; SAVIGNAC, 2013). 


\section{METODOLOGIA}

\subsection{Amostra}

A presente pesquisa utilizou-se da divisão do campus universitário em centros de ensino para a definir o universo a ser pesquisado. Atualmente a Universidade onde foi desenvolvido a pesquisa possui 12 centros de ensino em seu campus I, que agregam cursos de áreas comuns.

O universo da pesquisa compreendeu alunos pertencente a três centros de ensino, sendo eles, o Centro de Ciências Sociais Aplicadas (CCSA), o Centro de Educação (CE) e o Centro de Ciências Humanas Letras e Artes (CCHLA). A escolha dos grupos acadêmico se deu em função da diversidade de disciplinas ofertadas em cada um dos centros.

O CCSA corresponde ao centro de ensino onde estão alocados cursos como o de Contabilidade, Economia e Administração, o que torna comum a oferta de disciplinas como finanças, matemática financeira, análise de investimentos e outras. Enquanto isso, no CE e CCHLA estão alocados cursos como, o de pedagogia, licenciatura e psicologia, onde não são comuns a oferta de disciplinas relacionadas a finanças. Embora lidem com cursos distintos um ponto de ligação entre os dois cetros e fornecido por Hira (2009) ao sugerir que a gestão das finanças pessoais envolve conhecimentos multidisciplinares que permeiam os campos da economia, sociologia, psicologia e educação de jovens e adultos.

De acordo com Lucci et al. (2006) é de se esperar que alunos que cursem disciplinas voltadas a calculo e finanças tenham maior preparo para lidar com questões financeiras, dessa forma, assim como no estudo de Vieira et al. (2011) se optou por utilizar essa divisão como uma tentativa de identificar se a educação formal possui implicação no conhecimento financeiro desses alunos.

Embora nenhum dos cursos tenha disciplinas com foco na educação financeira, Holzmann e Miralles (2008) chamam atenção ao fato de não existir a necessidade de se desenvolver uma disciplina específica voltada a educação financeira. Neste contexto a amostra pesquisa compreende 188 alunos conforme demonstrado na tabela 1.

Tabela 1 - Amostra da pesquisa

\begin{tabular}{llcc}
\hline \multicolumn{1}{c}{ Curso } & Centro & Grupo Acadêmico & Total de alunos \\
\hline Ciências Contábeis & CCSA & 1 & 102 \\
Pedagogia & CE & 2 & 54 \\
Biologia & CCHLA & 2 & 1 \\
História & CCHLA & 2 & 8 \\
Musica & CCHLA & 2 & 1 \\
Serviço Social & CCHLA & 2 & 22 \\
\hline Total & & & 188 \\
\hline
\end{tabular}

Fonte: Dados da pesquisa.

Os 188 alunos respondentes da pesquisa estão distribuídos em três centros de ensino, entretanto devido ao fato dos cursos de Biologia, história e Música serem cursos de licenciatura, além do baixa números de respondentes dos cursos de Serviço social e Pedagogia em relação ao de contabilidade, a análise dos resultados foi tecida a partir de dois grupos acadêmicos doravante denominados Grupo Acadêmico 1(Composto de alunos do curso de Ciências Contábeis) e Grupo Acadêmico 2 (Composto de alunos dos cursos de Pedagogia, Biologia, História, Música e Serviço Social). 


\subsection{Instrumento de pesquisa e Procedimentos estatístico}

A coleta de dados se deu através de um questionário estruturado, formado por questões de múltiplas escolhas e aplicado de forma presencial. Antes de ser aplicado o questionário passou por uma fase de pré-teste aplicado com cinco alunos, cujo objetivo era verificar a clareza das questões e possíveis falhas do instrumento.

O questionário é composto de três seções que totalizam 15 perguntas. A primeira seção tem o propósito de possibilitar o estabelecimento do perfil sócio-econômico dos pesquisados, envolvendo questões como gênero, faixa etária, estado civil e renda.

A segunda seção é destinada a mensuração do grau de educação financeira dos respondentes e constitui uma adaptação do instrumento utilizado por Lusardi e Mitchell (2007, 2011) e Alessie, Rooji e Lusardi (2011). Desenvolvida originalmente para o U.S. Health and Retirement Study (HRS) é composto por três perguntas de múltipla escolha, sendo duas delas com baixo grau de complexidade envolvendo temas como cálculos simples e inflação, já a terceira questão possui uma complexidade maior ao envolver a diversificação de risco.

De acordo com Lusardi e Mitchell (2011) as perguntas são fundamentadas em quatro princípios básicos: A simplicidade, a relevância, a brevidade e a capacidade de diferenciação.

1) Simplicidade - implica que as questões devem envolver conceitos básicos semelhantes ao ABC aprendido durante o processo de alfabetização escolar;

2) Relevância - As questões deveriam se relacionar com conceitos do dia a dia financeiro das pessoas, buscando capturar informações gerais em vez de conceitos específicos;

3) Brevidade - O número de questões deveria ser reduzido ao mínimo de forma a permitir a aplicação em diferentes contextos;

4) Capacidade de diferenciação - As questões deveriam permitir a diferenciação dos níveis de conhecimentos.

Uma preocupação na elaboração do questionário corresponde a possibilidade de indução das respostas, para controlar esses efeitos, os respondentes podiam indicar que não sabiam a resposta (LUSARDI, MITCHELL, 2011).

$\mathrm{Na}$ terceira seção são apresentadas duas questões destinadas a permitir uma compreensão do comportamento dos estudantes em relação às finanças pessoais. Ambas as questões fazem uso de uma escala de liket de cinco pontos, a primeira delas (questão 14) desenvolvida por Lyons (2007) tem por objetivo verificar o grau de importância atribuída aos temas relacionados a orçamento, finanças pessoais, empréstimo e financiamento e aposentadoria. A questão 15 utiliza-se por sua vez tem por objetivo permitir um panorama do comportamento financeiro dos alunos.

\subsection{Análise estatística}

Os dados coletados foram tabulados com a ajuda da planilha eletrônica, onde foi calculado o nível de educação financeira de cada respondente. O cálculo do nível de educação financeira se deu a partir do índice de acertos de cada indivíduo, assim como efetuado por Alves et al. (2011) e calculado mediante o percentual de acertos em relação ao total.

A análise dos dados se deu a partir da estatística descritiva, da diferença de média e da análise de correlação.

Para verificar se existem diferenças entre o nível de educação financeira dos alunos do Grupo Acadêmico 1 e o Grupo Acadêmico 2, assim como as diferenças existente entre pessoas com diferentes perfis (Gênero, idade, renda e etc), foi utilizado um teste de média. 
Devido os dados não apresentarem os pré-requisitos necessários para o desenvolvimento de um teste paramétrico, utilizou-se a estatística não-paramétrico de Mann-Whitney e KruskalWallis (FIELD, 2009).

O teste de Mann-Whitney é usado quando se compara indivíduos diferentes em cada condição tornando-se a alternativa adequada para a presente pesquisa, ele corresponde ao equivalente não paramétrico do teste t de student e é calculada a partir da escores originados da ordenação das observações (DANCEY; RAIDY, 2013).

O teste de Kruskal-Wallis corresponde a uma generalização do teste de Mann-Whitney, isto é uma aplicação para mais de dois grupos, sendo ele um equivalente não paramétrico ao teste ANOVA (DANCEY; RAIDY, 2013).

Por fim com o objetivo de relacionar o nível de educação financeira dos alunos ao comportamento indicado nas questões 14 e 15 foi utilizado a correlação de Spearman que de acordo com Field (2009) é utilizada quando os dados não obedecem aos pressupostos necessários para um teste paramétrico.

\section{ANÁLISE DOS DADOS}

\subsection{Perfil dos respondentes}

Foram considerados 188 questionários aplicado com os dois grupos acadêmicos. O grupo acadêmico 1 é representado por 100 alunos do curso de Ciências Contábeis, enquanto o grupo 2 é formado por 88 alunos distribuídos nos cursos de Pedagogia (28,7\%), Licenciatura em Biologia (0,5\%), Licenciatura em História $(4,3 \%)$, Serviço social $(11,7 \%)$ e Licenciatura em Música (0,5\%). O perfil desses alunos está discriminado na tabela 2.

Tabela 2- Perfil dos respondentes

\begin{tabular}{llcc}
\hline & Características & Frequência & Percentual (\%) \\
\hline Gênero & Masculino & 68 & 36,2 \\
& Feminino & 120 & 63,8 \\
\hline Faixa etária & Até 20 anos & 57 & 30,32 \\
& De 20 a 26 anos & 101 & 53,72 \\
& DE 27 a 33 anos & 14 & 7,45 \\
& Acima de 34 anos & 16 & 8,51 \\
\hline Estado Civil & Solteiro & 161 & 86,6 \\
& Casado & 19 & 10,2 \\
& Divorciado & 4 & 2,1 \\
& Outros & 2 & 1,1 \\
\hline Local de moradia & Zona Rural & 9 & 4,8 \\
& Zona Urbana & 179 & 95,2 \\
\hline Possui alguma religião? & Sim & 152 & 81,7 \\
& Não & 34 & 18,3 \\
\hline Grupo acadêmico & Um & 100 & 53,2 \\
\hline Exerce atividade remunerada? & Dois & 88 & 46,8 \\
\hline
\end{tabular}

Nota: As diferenças no total das respostas representam dados faltosos.

Fonte: Dados da pesquisa. 
Em sua maioria os alunos pesquisados são do gênero feminino, com idade entre 20 e 26 anos, solteiros, moradores da zona urbana e praticantes de alguma religião.

No que tange o gênero dentre os 188 alunos 68 são do gênero masculino e 120 do gênero feminino, o grupo acadêmico 1 apresentou 47 alunos do gênero masculino enquanto o grupo acadêmico 2 apresentou apenas 21 , sugerindo uma predominância feminina no grupo acadêmico 2.

Quanto à faixa etária a maioria dos alunos $53,7 \%$ possui idade de 20 a 26 anos, o grupo acadêmico 1 é aquele que concentra o maior número de alunos nessa faixa etária. $30,2 \%$ possuem idade até 20 anos, o grupo acadêmico 2 representam 54,36\% dos alunos até 20 anos.

Entre os participantes da pesquisa 80,9\% declararam seguir uma religião, no grupo acadêmico 1 apenas dez alunos não seguem uma religião, enquanto que no grupo acadêmico 2 esse número aumenta para 24. Como um país laico e de se esperar uma diversidade religiosa entre os entrevistados, a maioria é a débito dos preceitos da religião Católica Apostólica Romana correspondendo a 40,4\% dos pesquisados.

Dentre os 154 alunos apenas 50,8\% exercem atividades remuneradas, sendo que $71,3 \%$ possuem renda pessoal de até setecentos e vinte e quatro reais (Incluindo os alunos que não exercem atividade remunerada, ou seja, tendo renda igual à zero). Vinte e três alunos possuem renda acima de $R \$ 724,00$ e inferior a $R \$ 1000,01$, quatorze possuem renda de $R \$$ 1000,01 a $\mathrm{R} \$ 1500,00$, nove pessoas possuem de $\mathrm{R} \$ 1500,01$ a $\mathrm{R} \$ 2500,00$ e oito pessoas tem sua renda acima de $\mathrm{R} \$ 2000,00$.

Quanto a renda familiar dos alunos, constatou-se que a distribuição de número de alunos para cada faixa salarial foi bem consistente. $22,9 \%$ dos alunos possuem renda familiar de 724 a 1000 reais, $21,23 \%$ possui renda de 1000,01 a 1500 reais, 22,3\% têm sua renda familiar de 1500,01 a 2500 reais, $18,6 \%$ tem sua renda familiar de 2500,01 a 4000,00 reais e $14,9 \%$ possuem renda familiar acima de 4000 reais.

\subsection{Nível de Educação Financeira}

Como descrito na seção 3.2 (Instrumento de pesquisa) o nível de educação financeira foi mensurado usando conceitos básicos em relação às finanças pessoais. De modo que as três questões buscaram verificar a compreensão dos entrevistados com relação a habilidades matemática, entendimento da inflação e investimentos.

No que tange a habilidade matemática dos alunos, foi apresentada a seguinte situação: "Suponha que você tinha $\mathrm{R} \$ 100,00$ em uma conta de poupança e a taxa de juros é de $2 \%$ ao ano. Após 5 anos quando você acha que teria em sua conta se você deixou o dinheiro crescer? ", os resultados e alternativas disponíveis estão apresentadas a seguir na tabela 3.

Tabela 3 - Cálculo simples

\begin{tabular}{lcccc}
\hline & Grupo acadêmico 1 & Grupo acadêmico 2 & Total & \% \\
\hline Mais de R \$ 110,00 & 59 & 38 & 97 & $51,60 \%$ \\
Exatamente R \$110,00 & 36 & 31 & 67 & $35,64 \%$ \\
Menos de R 110,00 & 02 & 06 & 08 & $04,26 \%$ \\
Não sei & 03 & 13 & 16 & $08,51 \%$ \\
Total & $\mathbf{1 0 0}$ & $\mathbf{8 8}$ & $\mathbf{1 8 8}$ & $\mathbf{1 0 0 \%}$ \\
\hline
\end{tabular}

Fonte: Dados da pesquisa.

Conforme demonstrado cerca de metade dos alunos $(51,60 \%)$ conseguiram responder a questão, enquanto isso, nos Estados Unidos, Lusardi e Mitchell (2006) evidenciaram um 
percentual de acerto 83,5\%, e na Holanda, Allessie, Rooji e Lusardi (2011) encontraram um percentual de acertos de $84,83 \%$.

Percentualmente verifica-se que o grupo acadêmico 1 apresentou desempenho superior em relação ao grupo acadêmico 2, consistente com isso Lusardi e Mitchell (2011) demonstram que pessoas cuja formação as habilitam para o desenvolvimento de um raciocínio matemático geralmente apresentam bom desempenho em problemas desse tipo.

Verifica-se ainda que o grupo 02 apresentou maior tendência a responder que não sabia, além disso, os dados ainda revelam que as mulheres também apresentaram maior disposição a apontar que não dominavam o assunto, uma vez que de 16 alunos que disseram não saber a resposta, 11 deles eram do gênero feminino.

No que se refere a inflação foi proposta aos alunos a seguinte proposição: "Imagine que a taxa de juros em sua conta poupança foi de $1 \%$ ao ano e a inflação foi de $2 \%$ ao ano. Após 1 ano, o quanto você seria capaz de comprar com o dinheiro nesta conta? ". Todas as alternativas disponíveis, assim como as respostas obtidas estão dispostas na tabela 4.

Tabela 4 - Inflação

\begin{tabular}{lcccc}
\hline & Grupo acadêmico 1 & Grupo acadêmico 2 & Total & \% \\
\hline Mais que hoje & 09 & 11 & 20 & $10,63 \%$ \\
Exatamente a mesma quantia & 03 & 13 & 16 & $08,51 \%$ \\
Menos que hoje & 79 & 44 & 123 & $65,43 \%$ \\
Não sabem & 09 & 18 & 27 & $14,36 \%$ \\
Não responderam & - & 02 & 02 & $01,06 \%$ \\
Total & $\mathbf{1 0 0}$ & $\mathbf{8 8}$ & $\mathbf{1 8 8}$ & $\mathbf{1 0 0 \%}$ \\
\hline
\end{tabular}

Fonte: dados da pesquisa.

Os resultados dispostos evidenciam que $65,43 \%$ dos alunos pesquisados demonstraram conhecimento sobre o tema, de acordo com Lusardi e Mitchell (2011) geralmente as pessoas conhecem e lidam melhor com o problema da inflação quando o país onde residem experimentou períodos inflacionários recentemente. No Brasil essa condição foi uma realidade até 1994 quando houve a instituição do plano real e a estabilização da moeda, entretanto dos 123 alunos que responderam corretamente à questão de pesquisa, 83,73\% possuíam idade até 26 anos, o que implica que durante o período de inflação esses alunos viveram sua infância o não eram nascidos.

A última questão abordada diz respeito ao risco dos investimentos, e trazia o seguinte enunciado: "A compra de uma única ação normalmente proporciona um retorno mais seguro do que um fundo mútuo de ações". Os resultados para essa questão estão dispostos na tabela 5 .

Tabela 5 - Investimento

\begin{tabular}{lcccc}
\hline & Grupo acadêmico 1 & Grupo acadêmico 2 & Total & \% \\
\hline Verdadeiro & 09 & 18 & 27 & $14,36 \%$ \\
Falso & 68 & 44 & 112 & $59,57 \%$ \\
Não sei & 23 & 26 & 49 & $26,06 \%$ \\
Total & $\mathbf{1 0 0}$ & $\mathbf{8 8}$ & $\mathbf{1 8 8}$ & $\mathbf{1 0 0 \%}$ \\
\hline
\end{tabular}

Fonte: Dados da pesquisa.

No aspecto do trade-off risco e retorno verificou-se que cerca de $60 \%$ dos entrevistados responderam corretamente a questão, os resultados foram próximos ao encontrado por Alissie, Rooij e Lusardi (2011) na Holanda, onde cerca de $50 \%$ dos pesquisado responderam corretamente, os autores justificam os resultados como uma consequência da amostra pesquisada ser predominantemente jovem e em muitos casos não serem responsáveis pela gestão de sua renda, embora na presente pesquisa também exista uma 
predominância de jovens cerca de $50 \%$ dos alunos que responderam corretamente possuem independência financeira, não explicando completamente o resultado, entretanto Vieira, Bataglia e Sereia (2011) salientam que no Brasil geralmente as pessoas não se planejam no que tange o longo prazo, implicando da não existência do hábito de poupar, principalmente devido ao já citado período inflacionário vivenciado no país. Ainda com relação ao risco é possível verificar um maior percentual de acertos do grupo acadêmico 1 em relação ao grupo acadêmico 2.

Quanto aos alunos que responderam não saber a resposta da questão, os dados evidenciaram que das 49 respostas, 36 é do gênero feminino. Esse resultado juntamente com os resultados das questões envolvendo cálculo e inflação indicam uma maior disposição das mulheres em relatar sua falta de conhecimento do assunto, segundo Lusardi e Mitchell (2006) isso ocorre devido ao fato dos homens serem mais excessivamente confiantes, isto é, superestimar suas habilidades, tornando-os menos propensos a assumirem a falta de conhecimento.

Utilizando da metodologia de Alves et al. (2011) a partir dos resultados das questões expostas anteriormente foram calculados os níveis de educação financeira dos alunos.

Tabela 6- Nível de educação financeira

\begin{tabular}{lcccc}
\hline \multicolumn{1}{c}{ Total de acertos } & Grupo acadêmico 1 & Grupo acadêmico 2 & Total & \% \\
\hline $0 \%$ & 14 & 21 & 35 & $18,62 \%$ \\
$33,33 \%$ & 28 & 34 & 62 & $32,98 \%$ \\
$66,67 \%$ & 55 & 33 & 88 & $46,81 \%$ \\
$100 \%$ & 03 & 00 & 03 & $01,60 \%$ \\
Total & $\mathbf{1 0 0}$ & $\mathbf{8 8}$ & $\mathbf{1 8 8}$ & $\mathbf{1 0 0 \%}$ \\
\hline
\end{tabular}

Fonte: Dados da pesquisa.

Baseado na tabela é possível perceber que dos 188 alunos, 46,81\% tiveram um desempenho satisfatório com um percentual de acertos de 66,67, 35 alunos não foram capazes de responder nenhum dos problemas sugeridos, 32,98\% tiveram um desempenho ruim e apenas $1,60 \%$ dos cento e oitenta e oito acertaram todas as questões. Analisando de forma geral $51,60 \%$ não possuem conhecimento suficiente para gerir suas finanças, $46,81 \%$ possuem um conhecimento considerável, mas não ótimo e apenas três conhecem bem determinados conceitos acerca das finanças pessoais.

Objetivando identificar o perfil de risco dos alunos utilizou-se da metodologia não paramétrica de Mann-Whitney U e Kruskal-Wallis para verificar os grupos com maior conhecimento financeiro. Os testes foram desenvolvidos relacionando o nível de educação financeira com o perfil dos alunos.

Tabela 7- Diferença de média nível de educação e características individuais

\begin{tabular}{|c|c|c|}
\hline Variável & Teste & P-valor \\
\hline Gênero & Mann-Whitney U & 0,003 \\
\hline Faixa etária & Kruskal - Wallis & 0,063 \\
\hline Estado Civil & Kruskal - Wallis & 0,418 \\
\hline Região onde mora & Mann-Whitney U & 0,997 \\
\hline Religião & Mann-Whitney U & 0,243 \\
\hline Curso & Kruskal - Wallis & 0,021 \\
\hline Trabalha & Mann-Whitney U & 0,219 \\
\hline Renda pessoal & Kruskal - Wallis & 0,318 \\
\hline Grupo & Mann-Whitney U & 0,003 \\
\hline Renda familiar & Kruskal - Wallis & 0,844 \\
\hline
\end{tabular}

Nota: Nível de significância de 5\%.

Fonte: Dados da pesquisa. 
Os resultados dos testes para o gênero são consistentes com os trabalhos de Chen e Volpe (2002); Alessie, Rooij e Lusardi (2011); Kapper, Lusardi e Panos (2012) e Arrondel, Debbich e Savignic (2013) onde os indivíduos do gênero masculino apresentaram conhecimento financeiro superior ao conhecimento financeiro do gênero feminino.

Também se verificou a existência de diferenças estatísticas entre os grupos acadêmicos estudados. Os alunos do grupo acadêmico 1 apresentaram nível médio de conhecimento superior ao grupo acadêmico 2 confirmando a expectativa de Lucci et al. (2006) em relação a alunos cujo estrutura curricular apresentam disciplinas como matemática financeira, economia e finanças.

\subsection{Comportamento e dinheiro}

Conforme mencionado na metodologia a questão 14 tinha por objetivo verificar o grau de importância atribuída pelos indivíduos a seis temas relacionados a comportamento financeiro:

- Gestão financeira e orçamento;

- Cartões de crédito;

- Empréstimo para a compra de carro;

- Financiamento de uma universidade;

- Poupar e investir;

- Planejar aposentadoria.

Em geral os alunos consideram a gestão das finanças pessoal e o orçamento doméstico como uma importante ferramenta de planejamento $(2,19)$, dos 188 alunos, 89 classificou o tema como muito importante ou importante, dente esses alunos $50 \%$ tinham nível de educação financeira igual a zero, o que sugere que mesmo com baixo conhecimento financeiro esses alunos reconhecem a importância atribuída ao tema.

Quanto a ter um cartão de crédito, os alunos em geral não possuem uma opinião formada quanto ao tema $(2,83), 29,34 \%$ o consideram sem importância e 35,3\% consideram importante ou muito importante. Do grupo acadêmico $237,65 \%$ indicaram o tema como importante, enquanto que no grupo acadêmico 1 esse percentual é de 33,33\%. No que se refere aos alunos que indicaram a não importância, esses percentuais são de respectivamente $15,29 \%$ para o grupo acadêmico 2 e $22 \%$ para o grupo acadêmico 1 , indicando uma maior importância atribuída pelo grupo acadêmico 2 .

No que se refere ao endividamento de longo prazo, duas opções foram apresentadas aos alunos com propósitos distintos, a primeira delas corresponde ao financiamento para aquisição de um veículo. Em um aspecto geral o resultado indica que o tema pode ser classificado entre pouco importante e um tema a qual não se tem opinião formada, uma vez que de acordo com a média obtida da escala de liket 3,25.

A segunda opção refere-se a importância atribuída ao financiamento destinado a custear uma faculdade, embora se trate de uma questão de endividamento, o assunto é tratado por muitos estudiosos como um investimento em capital humano (LIMA, 1980). Nesse aspecto os alunos indicaram o tema entre importante e um tópico sem opinião formada, $51,93 \%$ dos alunos não expressaram opinião ou não consideram o tema importante o que resultou em uma média de 2,75 , esse resultado pode ser explicado pelo fato da amostra pesquisada se tratar de alunos de uma universidade pública.

Tanto no que se refere ao empréstimo para compra de um automóvel, como o financiamento educacional não houve uma predominância de grupo acadêmico em relação ao outro. 
Assim como indicado por Hira (2009) e a OCDE (2005) a poupança e o investimento deve ser uma das preocupações dos indivíduos, de acordo com os resultados obtidos, de maneira geral esse tema é considerado como importante por parte dos pesquisados $(2,26)$. Aproximadamente $48,90 \%$ dos alunos atribuem alta relevância ao tema, estando entre eles todos os alunos com nível de educação financeira igual a $100 \%$, pouco menos da metade dos alunos que tiveram nível de educação financeira igual a $66,67 \%$ e $33,33 \%$, é exatamente a metade dos que tiveram nível de educação financeira igual a zero.

O último ponto abordado era o planejamento da aposentadoria assim como o tópico anterior (Poupança e investimento) esse corresponde a um tema relevante entre os alunos (2, 46), dentre as respostas obtidas $42,70 \%$ os alunos assumem esse tópico como muito importante.

Para relacionar as respostas obtidas na questão 14 ao nível de educação financeiras dos alunos foi realizado o teste de correlação de Spearman relacionando as respostas obtidas ao nível de educação financeira obtido.

Tabela 8 - Análise da importância percebida e nível de educação financeira

\begin{tabular}{|c|c|}
\hline Afirmativa & Coeficiente de correlação \\
\hline Gestão financeira e orçamento & $-0,058$ \\
\hline Cartões de crédito & $-0,093$ \\
\hline Empréstimo para a compra de um carro & 0,027 \\
\hline Financiamento de educação universitária & $-0,047$ \\
\hline Poupar e investir & $-0,05$ \\
\hline Planejamento da aposentadoria & $-0,103$ \\
\hline
\end{tabular}

Nota 1: Correlação de Spearman entre a importância atribuídas e o nível de educação financeira dos alunos.

Nota 2: * Significativo a 5\%.

Fonte: Dados da pesquisa.

Conforme demonstrado na tabela 08 os resultados das correlações não foram significativos, implicando que não possível afirmar que pessoas mais educadas financeiramente atribuem maior grau de importância aos temas apresentados.

A última questão (questão 15) possibilitou colher informações sobre a gestão financeira de cada um dos indivíduos sobre as perspectivas da poupança, endividamento e autoconhecimento.

Dos 188 alunos, 50,53\% afirmaram possuir algum tipo de poupança, dentre eles, aproximadamente 64\% desempenha alguma atividade remunerada, implicando que mesmo indivíduos que não exercem também possuem reservas financeira, podendo essas ser originadas de vínculos anteriores. Quando perguntado da importância de poupar e investimento 118 alunos expressaram sua importância, enquanto que 95 demonstraram alinhamento de suas preferências e ações.

Em sua maioria $74,73 \%$ os discentes afirmam que nunca tiveram ou tem seu nome inscrito no Serviço de proteção ao crédito- SPC ou SERASA, apenas cerca de $26 \%$ afirmaram que já tiveram ou que tem. 24,32\% afirmaram já possuir dívidas antes de iniciar o curso, 26,52\% contraíram dívidas após iniciar o curso.

Embora a educação financeira conforme indicada por Savoia, Saito e Santana (2007) corresponda uma direção para a tomada de decisão financeira segura e fundamentada e que de acordo com Potrich, Vieira e Silva (2016) ela corresponde ao caminho para o desenvolvimento da confiança necessária para gestão financeira pessoal, Barberis e Thaler (2002) chamam atenção para o aspecto cognitivo, e sua possível consequência no processo decisório financeiro. 
De acordo com Fischhoff, Slovic e Lichtenstein (1997) as pessoas acreditam saber mais do que de realmente sabem, implicando em um erro cognitivo conhecido como excesso de confiança. Quando questionado sobre o quanto de conhecimento financeiro os alunos possuem, verificou-se que $48,75 \%$ dos alunos disseram ter um bom conhecimento financeiro para gerir suas finanças pessoais, entretanto esse resultado não sugere a existência de um descompasso entre conhecimento e pensamento.

Ao afirmar que as pessoas não sabem como as decisões são tomadas Barzeman e Moore (2004) admitem que as pessoas não possuem consciência de como seu cognitivo interfere em suas decisões, dentre os pesquisados $58,89 \%$ dos alunos disseram ser racionais quando as decisões financeiras tomadas, o que demonstra um alinhamento do resultado obtido e a proposição dos autores.

Assim como para a questão 14 foi efetuada a correlação de Spearman dos resultados obtidos na questão 15 e o nível de educação financeira dos indivíduos.

Tabela 9 - Análise de comportamento e Nível de educação financeira

\begin{tabular}{lc}
\hline \multicolumn{1}{c}{ Afirmativa } & Coeficiente de correlação \\
\hline Tenho uma boa carga de conhecimento para gerir minhas finanças & $\mathbf{- 0 , 1 6 5 *}$ \\
Possuo reservas financeiras & 0,086 \\
Tenho ou já tive meu nome inscrito em um programa de proteção ao crédito & $-0,031$ \\
Possuía dívidas antes de começar o curso & $-0,058$ \\
Contraí dívidas após começar o curso & $\mathbf{- 0 , 1 5 1 *}$ \\
Sou totalmente racional & 0,062 \\
\hline
\end{tabular}

Nota 1: Correlação de Spearman entre a importância atribuídas e o nível de educação financeira dos alunos.

Nota 2: * Significativo a 5\%.

Fonte: Dados da pesquisa.

Conforme demonstrado na tabela 9, verificou-se uma correlação significativa, porém baixa entre o nível de educação financeira dos alunos e o grau de concordância quando a seu conhecimento financeiro. $\mathrm{O}$ sinal negativo do coeficiente demonstra pode ser explicado pelo argumento de Potrich, Vieira e Silva (2016) já citado anteriormente de que a educação financeira está relacionada com a confianças das pessoas na gestão de suas finanças pessoais.

Ainda de acordo com a tabela 9, é possível perceber uma correlação significativa, no entanto fraca entre o nível de educação financeira e a contração de dívidas após o início do curso. Definido por Ferreira (2006) como a contração de dívidas o endividamento não significa o não pagamento, dessa forma a correlação negativa implica dizer que os indivíduos mais educados possuem maior endividamento, porém não significa dizer que são mais inadimplentes.

\section{CONSIDERAÇÕES FINAIS}

O presente estudo teve como objetivo verificar a relação entre a educação financeira, características individuais, além do comportamento financeiro de estudantes de uma universidade pública da Paraíba, para isso utilizou-se de uma pesquisa de levantamento onde foi levantada características socioeconômica dos alunos, nível de educação financeira e seu comportamento em relação ao dinheiro.

A partir de uma amostra composta de 188 alunos onde 63,83\% eram gênero feminino, $53,7 \%$ possuem idade entre 20 e 26 anos, $86,56 \%$ dos alunos eram solteiros, mais de $90 \%$ seguiam alguma religião, 54,3\% eram graduandos em Ciências Contábeis e os demais se encontravam entre os cursos de Pedagogia, Serviço Social, Biologia, Música e História. Foi 
possível verificar que o nível de educação financeira dos alunos em sua maioria é entre baixo e razoável.

Além disso verificou-se que os fatores como graduação e gênero são estatisticamente significativos para com relação ao conhecimento financeiro dos alunos e sugerindo que alunos de cursos que possuem disciplinas como economia, finanças e matemática apresentam conhecimento financeiro superior em relação aos demais alunos. Assim como já demonstrado na literatura por autores como de Chen e Volpe (2002); Alessie, Rooij e Lusardi (2011); Kapper, Lusardi e Panos (2012) e Arrondel, Debbich e Savignic (2013) também foi encontrado que as pessoas do gênero feminino possuem conhecimento financeiro inferior em relação às pessoas do gênero masculino. Variáveis como idade; religião; estado civil e local em que se reside não demonstrou relevância estatística para identificação do perfil de risco dos alunos.

Quanto ao comportamento financeiro dos alunos verificou-se que geral os alunos atribuem importância aos temas gestão financeira e orçamento, poupar e investir e planejamento da aposentadoria, já o tema cartão de crédito não foi atribuída relevância, entretanto verificou-se que os alunos do grupo acadêmico 2 demonstraram mais relevância.

Também se verificou que a existência de relação estatística entre o nível de educação financeira e a confiança relatada pelos indivíduos para a gestão das finanças pessoais, além disso também se verificou uma relação entre o nível de educação financeira e a contração de dívidas após o ingresso no ambiente universitário.

O estudo tem como limitação a impossibilidade de generalização dos resultados, uma vez que a amostra utilizada é não probabilística, sendo indicada como sugestão de pesquisa uma replicação a partir de uma amostra representativa. 


\section{REFERÊNCIAS}

ALESSIE, Rob; ROOIJ, Maarten van e LUSARDI, Annamaria. Financial Literacy, Retirement Preparation and Pension Expectations in the Netherlands. Janeiro de 2011. Disponível em $<$ http://ssrn.com/abstract=1810548>. Acessado em 25/02/14.

ALVES, Rodrigo Araújo; el al. Educação Financeira: Uma Lacuna Na Formação Discente Na Área De Contabilidade? In: Adcont , 2011, Rio de Janeiro. Disponível em < http://www.facc.ufrj.br/ocs/index.php/adcont/adcont2011/paper/viewFile/384/59> acessado em $04 / 10 / 2013$.

ARRONDEL, Luc; DEBBICH, Majdi e SAVIGNAC, Frédérique. Financial Literacy and Financial Planning in France. Dezembro de 2013. Disponível em < http://ssrn.com/abstract=2374363 > acessado em 25/02/14.

AUGUSTINIS, Viviane Franco; COSTA, Alessandra de Sá Mello da; BARROS, Denise Franca. Uma Análise Crítica do Discurso de Educação Financeira: por uma Educação para Além do Capital. Revista Adm.made, Rio de Janeiro, v. 16, n. 3, p.79-102, set. 2012. Quadrimestral.

BARBERIS; Nicholas e THALER; Richard. A Survey of Behavioral Finance. Setembro de 2002. Disponível em< http://www.nber.org/papers/w9222 > acessado em $<12 / 12 / 2014$.

BAZERMAN, Max H.; MOORE, Dom. Processo decisório. 8. ed. Rio de Janeiro: Elsevier, 2014. 424 p. Tradução de: Daniel Vieira.

BEHRMAN, Jere R.at al. Financial Literacy, Schooling, and Wealth Accumulation.2010. Disponível em <http://repository.upenn.edu/parc_working_papers/32> acessado em 25/02/2014.

BIROCHI, Renê; POZZEBON, Marlei. IMPROVING FINANCIAL INCLUSION: TOWARDS A CRITICAL FINANCIAL EDUCATION FRAMEWORK. Revista de AdministraÇÃo de Empresas, São Paulo, v. 56, n. 3, p.266-287, jun. 2016

BONGOMIN, George Okello Candiya et al. Financial literacy in emerging economies: Do all components matter for financial inclusion of poor households in rural Uganda?. Managerial Finance, v. 43 , n. 12, p.1-25, jan. 2017.

BRASIL. Decreto $n^{\circ}$ 7397, de 22 de dezembro de 2010. Institui a Estratégia Nacional de Educação Financeira - ENEF, dispõe sobre a sua gestão e dá outras providências. Lex. Brasília, 22 dez. 2010. Disponível em: <http://www.planalto.gov.br/ccivil_03/_ato2007-2010/2010/decreto/d7397.htm>. Acesso em: 22 mar. 2018.

CHEN, H., \& VOLPE P. R. Gender Differences in Personal Financial Literacy Among College Students. Financial Services Review, 2002. Disponível em < http://maagblog.ysu.edu/financialliteracy/files/2009/03/volpe2.pdf> acessado em 24/02/14.

DANCEY, Christine P.; REIDY, John. Estatística Sem Matemática para Psicologia. 15. ed. São Paulo: Penso, 2013.

ENEF (Brasil). $2^{\mathbf{0}}$ Mapeamento Nacional das Iniciativas de Educação Financeira. 2018. Disponível em: 〈http://www.vidaedinheiro.gov.br/2-mapeamento/>. Acesso em: 10 maio 2018.

ENEF. Estratégia Nacional de Educação Financeira, 2008. Disponível em: $\langle$ http://www.vidaedinheiro.gov.br/Imagens/Plano\%20Diretor\%20ENEF.pdf > acessado em 25/02/2014.

FERREIRA. R. Como Planejar, Organizar e Controlar seu Dinheiro. Thomson IOB. São Paulo: 2006.

FIELD, Andy. Descobrindo a estatística usando o SPSS. 2. ed. Porto Alegre: Artmed, 2009. Tradução de: Lorí Viali. 
FISCHHOFF, Baruch; SLOVIC, Paul; LICHTENSTEIN, Sarah. Knowing with Certainty: The Appropriateness of Extreme Confidence. Journal Of Experimental Psychology: Human Perception And Performance, v. 3, n. 4, p.552-564, 1977.

FLORES, Silvia Amélia Mendonça; CAMPARA, Jéssica Pulino; VIEIRA, Kelmara Mendes. Propensão ao Endividamento no Município de Santa Maria (RS): Análise da Influência da Educação Financeira e de Variáveis Demográficas. In: SEMINÁRIOS EM ADMINISTRAÇÃO (SEMEAD), 15., 2012, São Paulo. Anais... . São Paulo: Semead, 2012. p. 1 - 16.

FREITAG, Viviane da Costa et al. A contabilidade para controle das finanças pessoais: A visão do acadêmico. In: Seminários em Administração (SEMEAD), 12., 2009, São Paulo. Anais... São Paulo: Universidade de São Paulo, 2009. p. 1 - 17.

GRÜSSNER, Paula Medaglia. Administração das Finanças Pessoais para a criação de patrimônio. UFRS, Porto Alegre, 2007. Disponível em < http://www.lume.ufrgs.br/handle/10183/21978> acessado em 23/06/14.

HASLEM, John A. Selected Topics in Financial Literacy. Janeiro de 2013. Disponível em < http://ssrn.com/abstract=2352918 > acessado em 25/02/2014.

HIRA, Tahira K. Personal Finance: Past, Present and Future. Dezembro de 2009. Disponível em < http://ssrn.com/abstract=1522299> acessado em 25/02/14.

HOLZMANN, R.; MIRALLES, M. P. The role, limits of, and alternatives to financial education in support of retirement saving in the OECD, Eastern Europe and beyond. The World Bank, out/ 2005. Disponível em: <ttp://info.worldbank.org/etools/library/view_p.asp?205715 > Acesso em 31 de maio de 2018.

JONSSON, Sara; SÖDERBERG, Inga-lill; WILHELMSSON, Mats. Investigation of the impact of financial literacy, risk attitude, and saving motives on the attenuation of mutual fund investors' disposition bias. Managerial Finance, v. 43, n. 3, p.1-29, 2017.

KLAPPER, Leora; LUSARDI, Annamaria e PANOS, Georgios A. Financial Literacy and the Financial Crisis. março de 2012. Disponível em < http://ssrn.com/abstract=2038765> Acessado em $25 / 02 / 2014$

LIMA, R. Mercado de trabalho: o capital humano e a teoria da segmentação. Pesquisa e Planejamento Econômico, IPEA, Vol. 10, 1, 1980.

LUCCI, Cintia Retz et al. A influência da educação financeira nas decisões de consumo e investimento dos indivíduos. In: SEMINÁRIOS EM ADMINISTRAÇÃO (SEMEAD), 9. 2006, São Paulo. Anais... São Paulo: SEMEAD, 2006. p. 1 - 12.

LUCENA, Wenner Glaucio Lopes; MACIEL, Rutênio Gleisson Costa. A precificação Psicológica relacionada ao Comportamento do Consumidor no Processo de Decisão de Compra de Bens ou Serviços. Gestão Contemporânea, Porto Alegre, ano 9, n. 12, p. 91-113, jul./dez. 2012. Disponível em: <http://seer2.fapa.com.br/index.php/arquivo> acessado em dezembro de 2014.

LUSARDI, Annamaria; MITCHELL, Oliveira S. Financial Literacy Around The World: An Overview, 2011. Disponível em < http://www.nber.org/papers/w17107> acessado em 23/06/13.

LUSARDI, Annamaria; MITCHELL, Olivia S. Financial Literacy and Retirement Preparedness: Evidence and Implications for Financial Education Programs, 2006. Disponível em < http://www.mrrc.isr.umich.edu/publications/papers/pdf/wp144.pdf> acessado em: 23/07/13

LUSARDI, Annamaria; MITCHELLI, Olivia S. Financial literacy and retirement preparedness: Evidence and implications for financial education. Business economics, v. 42, n. 1, p. 35-44, 2007. LYONS, Angela C. Credit Practices and Financial Education Needs of Midwest College

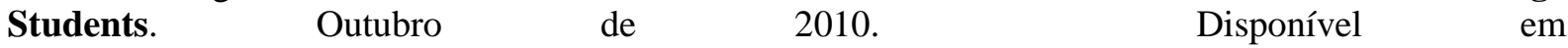
<http://papers.ssrn.com/sol3/papers.cfm?abstract_id=1060801. Acessado em 30/05/2018. 
OECD. Measuring Financial Literacy, questionnaire and guidance notes for conducting an Internationally Comparable Survey of Financial literacy. In: International Network on Financial Education: Cape Town, 2011, Paris. Anais... Paris, 2011.

ORGANISATION FOR ECONOMIC CO-•-OPERATION AND DEVELOPMENT OCDE. Recommendations on principles and good practices for financial education. 2005. Disponível em: 〈www.oecd.org/>. Acesso em: 20 maio 2018.

POTRICH, Ani Caroline Grigion; VIEIRA, Kelmara Mendes; SILVA, Wesley Mendes da. Development of a financial literacy model for university students. Management Research Review, v. 39, n. 3, p.1-30, 2016.

SAVOIA, José Roberto Ferreira; SAITO, André Taue; SANTANA Flávia de Angelis. Paradigmas da educação financeira no Brasil. Revista de Administração Pública. Rio de Janeiro, vol. 41, n. 6, p.1121-1141, 2007. Disponível em < http://bibliotecadigital.fgv.br/ojs/index.php/rap/> acessado em $24 / 02 / 2014$.

SILVA, Guilherme de Oliveira e et al. Alfabetização financeira versus educação financeira: Um estudo do comportamento de variáveis socioeconômicas e demográficas. Revista de Gestão, Finanças e Contabilidade, Salvador, v. 3, n. 7, p.279-298, set. 2019. Quadrimestral.

SPC. Indicadores Econômicos SPC Brasil e CNDL. 2017. Disponível em: <https://www.spcbrasil.org.br/wpimprensa/wp.../Análise-Inadimplência-PF-_-jan-1.pdf>. Acesso em: 20 maio 2018.

VIEIRA, S.f.a.; BATAGLIA, R.t.m.; SEREIA, V.j.. Educação Financeira e Decisões de Consumo, Investimento e Poupança: Uma Análise dos Alunos de Uma Universidade Pública do Norte do Paraná. Revista de Administração da Unimep, [s.1.], v. 9, n. 3, p.61-86, 30 dez. 2011. Instituto Educacional Piracicabano da Igreja Metodista.

VIEIRA, Saulo Fabiano Amancio; BATAGLIA, Regiane Tardiolle Manfre; SEREIA, Vanderlei José. Educação financeira e decisões de consumo, investimento e poupança: Uma análise dos alunos de uma universidade pública do norte do paraná. Revista de Administração da Unimep, v. 3, n. 9, p.1-26, set. 2011. Quadrimestral.

WORTHINGTON, A. C.. Predicting financial literacy in Australia. Financial Services Review, v. 15, p.59-79, jan. 2009. 